\title{
Correction to: Climate Control of Greenhouse System Using Neural Predictive Controller
}

\author{
Shriji V. Gandhi and Manish T. Thakker
}

Correction to:

Chapter "Climate Control of Greenhouse System Using Neural Predictive Controller"' in: D. Deb et al. (eds.), Renewable Energy and Climate Change, Smart Innovation, Systems and Technologies 161, https://doi.org/10.1007/978-981-32-9578-0_19

In the original version of the chapter, the following belated corrections have been incorporated: The author (Shriji V. Gandhi) affiliation "Government Polytechnic Ahmedabad, Ahmedabad, India" has been changed to "Gujarat Technological University, Ahmedabad, Gujarat, India" in the Frontmatter, Backmatter and in Chapter 19. The correction chapter and the book have been updated with the change. 